first place to its causing the blood to flow to the internal organs, then to the surface, resulting in cooling the body by elimination of heat. Surely nothing could be farther from the truth than this. According to my own experience and the impressions gained from rather wide reading on the subject, the chief effect of the cold bath is its stimulating effect upon the nerve centers. Take its effect upon the centers of respiration; it stimulates at once a deeper inspiration, and in that way overcomes the tendency to pulmonary complications; the effect upon the stomach is brought about in the same way. Take its effect on the nervous system-a patient who is in a profound coma, or perhaps delirious, under the cold bath will show signs of returning consciousness, or will fall asleep.

Dr. Loveland.- While typhoid fever may be properly treated by the Brand cold water method, or by antifebrin and antipyrin, it has always seemed to me that those who claim so much for these remedies in the treatment of typhoid fever overlook the fact of the etiology of the disease,-that typhoid is produced by a germ, or rather by a ptomaine resulting from the typhoid bacillus in the bowel; the poison being absorbed by the alimentary canal is taken up by the system, poisoning the nerve centers. So there should be an effort made to subdue the poison in the alimentary canal. I have tried the cold water treatment; I have used antifebrin to a considerable extent, but my typhoid fever treatment consists in disinfecting the alimentary canal. A disinfectant that will destroy the ptomaines in the alimentary canal it seems to me will have a much better effect than to rely upon such remedies as will reduce the fever without going to the cause of the disease. Several years ago Dr. Wilson of Philadelphia, gave us a treatment for disinfecting the alimentary canal, composed of carbolic acid and iodine; that was used for some time with good effect, but it was not ideal treatment. We need something which when taken into the alimentary canal will pass into the bowels without being absorbed from the stomach; iodine and carbolic acid to a large extent is absorbed from the stomach and it takes too long a time to get the patient from under the influence of it and to disinfect the bowel. Naphthalin, properly given, when it passes into the bowel will disinfect it to such an extent that those hard discharges the patient has in typhoid fever that are offensive, will be made non-offensive; the odor is entirely removed in a short time. When the alimentary canal is disinfected thoroughly you will have no use for antifebrin. I have treated these cases year after year and I know from experience that when you get the patient thoroughly under the influence of naphthalin, or any of that class of remedies, the temperature will remain so low that antipyretics are unnecessary.

Dr. C. G. Stockton, Buffalo, N. Y.-I feel very greatly indebted to Dr. Sihler for showing to me what determination of purpose can carry out, in what has seemed to most of us a very difficult matter, and I admire the way in which he has succeeded in carrying into the homes of the poor a means of relief which cannot be too highly spoken of. I have seen enough of typhoid fever in the homes of the poor under ordinary forms of treatment. to make me think that if this can be carried out with anything like success in the matter of detail, which has been done in Dr. Sihler's cases, the utmost good would come. That we have a fatality of the disease among the poor we all know. When we compare the statistics in private cases in the homes of the wealthy and the poor, we find a great difference. It makes a great deal of difference whether the patient is seen at first or at the end of a week. In hospital cases I have seen such great benefit from the Brand treatment that I think it is, so far as we now know, the best one to adopt. If I had ty- phoid fever I want the Brand treatment given me, because I shall be certain that when over it I will be in far better condition physically than after any other treatment. I have never seen patients come out with as strong hearts, as well preserved nervous systems, and in every way in as good condition as my ward patients during the last three years under this treatment.

Dr. C. Sinler, Cleveland, O.-I feel that the Brand treatment has not any too many friends here. I am a poor fellow to make friends; I don't think I ever convinced anybody of anything in my life. I find the logic of men differs and the logic of doctors differs, and of course we can not convince each other. As far as the men are concerned who have had no experience with the treatment, I do not listen to them. We have sulphur for the itch, mercury for syphilis and cinchona preparations for malaria-those are a few things with which we know we can do good, and in typhoid fever I think the Brand method has placed in our hands something that is equal. So far as pneumonia is concerned, if that is caused by the Brand treatment, we who use that method should see a good deal of it, but we don't. I would ask Prof.Quine whether the typhoid we have now is particularly liable to hemorrhage? It seems to me we lose more patients from hemorrhage than from fever. As to $\mathrm{my}$ case, of course I would be a brilliant diagnostician if I could diagnose every case of typhoid on the fifth day; the facts are the woman had typhoid fever before she was taken sick; the profuse local discharge, the rose spots, the course of the disease and the combined general symptoms proved to me that in that case I was right. As far as sponging is concerned, I know nothing about that. I thought it was a good thing in the Brand method that my patients know how to give the bath after I explain it to them. I would just as soon take a bath as to be rolled over and sponged. Just as the surgeon does not say that he can take care of a wound when he gets the case, one or two weeks after it has been made, so we do not claim success unless we can get our patients early, but our private patients ought to have the benefit of this treatment.

\section{VISCERAL PHLEBOTOMY.}

BY DR. GEORGE HARLEY, M.D., F.R.S. LONDON.

Corresponding Member of the Royal Academy of Seiences of Bavaria of the Royal Academy of Medicine of Madrid: Vice-President of the Royal Medical and Chirurgical Society, London, etc.

Pari passu with the recent advances made in scientific physiology and pathology have most marked changes and improvements taken place in the medical and surgical treatment of disease. Some of them have appeared startling by reason of their novelty, others have intimidated on account of their seeming temerity. Many have been stigmatized as chimerical. While not a few have been actually condemned as being beyond the pale of rational therapeutics. Nevertheless on better acquaintance most of them have been found to be as replete with wisdom as they have proved to be pregnant with advantage to the healing art. Visceral phlebotomy, of which I am about to speak, may not untruthfully be said to belong to the latter class. For when it was first introduced by me to the notice of the profession in $1886^{1}$ in the form of hepatic phlebotomy it was not only abused as a most dangerous, but stigmatized as a most unjustifiable operative procedure. Nevertheless, although only six years have glided away since its death knell was so vociferously sounded, instead 1 Hepatic Phlebotomy, Brit. Med. Jour., Nov. 13, 1886-1b. Jan. 15 
of having been consigned to an oblivious tomb, it is not only still alive and flourishing, but has had added to it a twin sister in the shape of pulmonary phlebotomy, by Dr. Christian Simpson, and now l am about to advocate the extension of this mode of curative procedure to every other come-at-able visceral organ of the body.

Thinking no simpler or more effective place of proving either the safety of, or the benefits to be derived from any novel system of treatment can be adduced than by quoting successful illustrative cases, I will not waste time in exposition; but at once briefly narrate two most successful examples which can neither be gainsaid nor doubted; and in order to save space, and yet put it in the power of those specially interested in the subject to obtain possession of the details in each case, I will cite cases that have elsewhere been published in extenso. The one by myself, ${ }^{2}$ the other by my son, Dr. Vaughan Harley :

Case 1.-The patient, a lady of intemperate habits, aged 38 , was not operated upon until she was supposed to be in a dying state, from the combined effects of a greatly enlarged hard and inflamed liver complicated with ascites and marked anasarca. After Dr. Dunbar Walker (whose patient she was) had rendered her insensible with the A. C. E. mixture, ${ }^{3} \mathrm{I}$ pierced the upper part of the liver from right to left with an eight inch long trocar of the diameter of between a No. 2 and 3 sized English catheter. The normal liver being at least two inches broad in an average sized woman, and this liver being greatly enlarged-several inches both laterally and perpendicularly-I felt perfectly safe in thrusting the eight inch trocar up to its very hilt. This was done with the hope that during its penetration it might wound one or more blood vessels of sufficient caliber to yield a free stream of blood. On withdrawing the end of the canula about an inch or two, blood issued freely, and twenty ounces were abstracted. The skin around was then closed with a piece of sticking plaster, and a bandage applied. Such was the benefit derived from the operation, that from the very next day the downward progress of the case was arrested. The liver decreased in size, and with the aid of tapping, the ascites and anasarca disappeared, and within three months the patient was so well and strong that she could walk a distance of three miles, and she never had a return of the disease.

Ca.e 2.-Is one of an entirely different character, cited with the view of showing, equally forcibly, the value of hepatic phlebotomy in a case of enlarged and inflamed liverthe seat of strumerous abscesses.

The patient was a country lad, aged 17, whom I was called to see by Drs. Cooper, They and Surgeon Heaven. The liver dullness extended from the right nipple level down to two inches below the umbilicus, and four to the left of the mucial line. Phlebotomy was performed while the patient was under the influence of the A. C. E. mixture. But although the liver was punctured in several places, such was the hardness and compactness of its tissues (on account of the inflammation) that only a very little blood was obtained. Fortunately, however, profuse hemorrhage took place some hours afterwards ${ }^{4}$ from the wounded liver through the bile ducts into the intestines, with the result that within thirty-six hours the liver had diminished in size. no less than an inch and a half all round, which made an enormous diminution, and within six days the first ab-

2 Brit. Med. Jour., Nov. 13, 1886.

3 This is a safer form of anxsthetic than chloroform, consisting of part of absolute alcohol, 2 parts of chloroform, and 3 parts of sulphuric ether proposed by me, and recommended by the committee "On the Uses and Effects of Chloroform," appointed by the Royal Medical Chirurgical Society of London, (of which I was a member). See the Transactions of 1864, p. 341 . scess had pointed and been emptied. In three days more a second abscess was equally emptied and on the thirty-eighth day the patient returned to his home in Lincolnshire, a distance of 120 miles, without a single bad symptom. The results of these two cases, must I think, con vince even the most skeptical, not only of the safety of this operative mode of procedure, but of its utility as a curative agent; for without it, I have not the slightest hesitation in saying that both of these patients who were subjected to it would have been in their graves within a few days.

I now come to pulmonary phlebotomy first proposed and practiced by Dr. Christian Simpson. ${ }^{5}$ This, I consider to be the most difficult form of visceral phlebotomy. From the fact that from lungs being contained within the ribs, and constantly contracting and expanding it is impossible by the application of an external bandage to bring the thoracic parietes into firm contact with the orifice of the wound made in pulmonary tissues, so as to effectually closeit. Consequently the closure of the wound in the lung after the operation must be effected by the resistence of the pulmonary tissues being sufficient to retain a blood clot in the channel made by the trocar. In order to favor this, Dr. Simpson adopted the plan of "after the withdrawal of twelve ounces of blood the canula was held in situ with the finger over the end, to allow a clot forming, and then it was slowly withdrawn." . . . "The patient was immediately and markedly relieved, both as regards the cerebral (she had been comatose G. H), and pulmonary conditions. No effusion took place; there was only trifling hemoptyosis, and a suspicion of a small patch of pleurisy, without a rise of temperature." Dr. Simpson employed aspirating needles in his operations and although they did not prove like mine successful this can scarcely be said to have been due to any fault in the operation, but to the diseases complicating the pulmonary congestion for which the phlebotomy was had recourse to. Two of them being cases complicatod with advanced organic heart disease, and the others, two cases of equally incurable Bright's disease.

Having thus shown that the apparently heroic method of extracting blood directly from an inflamed internal organ can not alone be practiced with safety on a favorably placed gland like the liver, but on one of the most unfavorably placed organs of the body for the successful performance of the operation, namely the ever moving lungs, I think I need scarcely dread censure if I boldly recommend the performance of visceral phlebotomy on every suitably situated internal organ, (when it is in a seriously congested condition) in preference to the application of leeches or cupping glasses to the external parietes over it, seeing that the cutaneous blood vessels have in no case whatever any direct communication with the internal organs lying beneath them. Consequently the theory of doing good is but a delusion, and the practice of leeching and cupping but a snare, if done with the intention of directly diminishing the amou $t$ of blood circulating through or stagnating in a $\mathrm{v}^{\mathrm{n}_{\text {sceral }}}$ organ. As the withdrawal of blood from $i$ he cutaneous capillaries can only act beneficially int such cases, in so far as it diminishes the entire a mount of blood in the body, and seeing that the largest of the internal organ

4 This case is reported in full by my so $Q$ Dr. Vaughan Harley in bis aper "On Abscess of the Liver," Brit. Med. Jour. Nov. 23, 1889

¿ "A New Method of Bleeding in some Forms of Pulmonary Congestion with Four C ases" Lancet (London) No . 1, 1890. 
forms but a small proportion of the whole frame, its thus diminished blood supply cannot be but an insignificant one. Whereas by my proposed method, as shown in the case of the liver where twenty ounces of blood were directly withdrawn, and Dr. Simpson's of the lung, where twelve ounces of blood equally directly extracted from the organ, as much or as little blood can be removed from the congested parts as the operator thinks needful.

Within the last few days, I proposed extracting blood from a tender, greatly enlarged and inflamed spleen; but was thwarted by the nervous apprehensions of an imperfectly educated coadjutor, from his not knowing, that even needles as large as No. 3 sized catheters can be not only thrust into, but kept for twenty minutes in the ventricles of the hearts of living dogs, with perfect impunity. 'Tis knowledge which inspires surgical confidence and without it no one ought to attempt visceral phlebotomy.

For those who are about to have recourse to it as a curative measure for the first time, the following hints, perhaps, may be of service:

1. If it be deemed advisable to render the patient insensible, induce anæsthesia of the skin at the point selected for puncture, by the local application of the hydrochlorate of cocaine.

2 . Select the seat of puncture, and give such a direction to the trocar as will ensure the point of its entrance with the organ, being brought into direct contact into the parietes by the application of pressure to them by a bandage after the completion of the operation, in order that the mouth of the wound in the organ may be thereby readily and effectually closed.

3. Let the trocar or aspirating needles be of the size of a No. 2 or 3 sized English catheter, and sufficiently long to penetrate deeply into the organ operated on, without there existing any risk of entirely transfixing it.

4. Let the direction of the instrument be such as to avoid its puncturing any large blood vessel.

5 . When all these points have been attended to it will save the patient pain if the instrument be rap. idly and at once thrust into the organ to the full depth it is intended to puncture.

6 . If no blood flows, then slowly, and by distinct degrees, withdraw the canula, in the hope that a sufficiency of blood will ooze from the transfixed capillaries into the canal made in the organ by the instrument as will yield a free stream and enough for the required purpose.

7. When the wished for amount of blood has been obtained, before withdrawing the canula aitogether from the organ, but just before it leaves it, in order to obtain a blood clot to stop up the wound with, place the finger on the mouth of the canula and keep it there till a clot has had time to form both in its interior and in the canal made in the organ itself by the instrument.

8. The next point is to get the clot in the canula to break off from that in the canal so as to leave the latter behind, in order that by its presence there it may prevent any oozing of blood from the organ, after the withdrawal of the instrument. This is best done, I think, by giving a slight twist to the canula at the moment it is felt to leave the organ. And the resistence of the tissues of the organ will cause them to contract sufficiently firm round the clot within it to prevent its being drawn out along with the canula.
9. All that now remains to be done is to place an inch square sized piece of adhesive plaster over the seat of the external puncture, and bind a pad over it with a long flannel bandage, sufficiently firm to insure the internal surface of the parietes being brought into close contact with the orifice of the wound in the organ; the more effectually to prevent the possibility of accidental internal hemorrhage taking place. All I have to add is that if I am not very much mistaken the day is not far distant when the old fashioned, erroneous, as well as unsatisfactory mode of withdrawing blood cutaneously, will be totally abolished in all cases of inflammation and congestion of internal organs, having no circulatory connection with the skin, and that the practice of visceral phlebotomy will become the recognized orthodox method of depletion in such cases.

\section{NECROLOGY.}

Dr. Louis A. Destrampes.-President Oliphant of the Louisiana State Board of Health, received July 14, 1893, a cablegram from Bocas del Toro, United States of Colombia, announcing the death of Dr. Louis A. Destrampes, quarantine physician at that port. Dr. Destrampes was a well known citizen of New Orleans, a native of Havana, Cuba, where he was born in 1831 . He had been a resident of New Orleans for thirty years.

Dr. David Harlan died July 12, at the age of 84 years, at his home at Churchville, Harford county, Md. Dr. Harlan was born near Stafford, in Harford county. He leaves four sons: Dr. Herbert Harlan, Judge Henry D. Harlan of Baltimore, W. B. Harlan and David E. Harlan. He was a member of the board of visitors to the Naval Academy at Annapolis, and a medical director in the United States Navy and was one of the best known and most highly respected citizens of Harford county.

Dr. Harlan began the study of medicine in 1829 under Dr. John Archer of Rock Run. He afterward attended the University of Maryland. He graduated in 1832 and located in Chestertown, Kent county, and practiced there for three years.

He applied for admission to the United States Navy and was examined in 1835 and commissioned as assistant surgeon. In the spring of 1835 he sailed from New York on the Peacock to Rio Janeiro, around the Cape of Good Hope to Zanzibar, to Muscat, Bombay, Ceylon, Bangkok, Siam and Canton, China. While in Siam the Asiatic cholera broke out aboard the Peacock. Dr. Harlan had charge of the vessel and lost but one of the crew. Upon his return to the United States two years later he was presented with a sword by the members of the crew. In 1872 he was stationed at the naval hospital on the government farm at Annapolis. He was promoted to the rank of medical director in 1871 and upon reaching the age of sixty-two he retired. He built Trinity Protestant Episcopal church at Churchville and was often a prominent member of diocesan conventions.-Maryland Medical Journal.

To Drain the Red River Valley.-Gov. Nelson of Minnesota, July 15 appointed an auditing committee under whose auspices the work of draining the Red river valley will be conducted in accordance with a law passed by the legislature. The committee consists of Gov. Nelson, Secretary of of State Brown, Ezra F. Valentine of Breckinridge, and Nelson D. Miller, chief engineer of the Great Northern railway. The work will proceed without delay. The drainage is rather for agricultural than sanitary purposes. 